\title{
Ethnobotanical Study of Medicinal Plants in Sub Zoba Gala- Nefhi, Zoba Maekel, Eritrea
}

\section{Milka Brhane, Tsinat Girmay, Biniam Yamane and Kunduru Surender Reddy*}

Department of Biology, Eritrea Institute of Technology, Eritrea

*Corresponding author: Kunduru Surender Reddy, Department of Biology, Eritrea Institute of Technology, Mai Nefhi, Asmara, NE Africa Eritrea,Email: ksreddy.eit@gmail.com; kundurusr@eit.edu.er

\section{Research Article}

Volume 2 Issue 5

Received Date: July 02, 2018

Published Date: July 24, 2018

\section{Abstract}

Ethnobotanical study of medicinal plants was observed in Sub-Zoba Gala-Nefhi of Zoba-Maekel and it is one of the Zobas of Eritrea. The study conducted is an attempt to their medicinal value and its application of plants to human beings. Its record, identification and indigenous knowledge over its usage, the treatment of recorded diseases and healing properties were also noticed. They used different parts of medicinal plants and extracting by different methods such as boiling, roasting, crushing, smoking/inhaling, powdering, latex collection etc and the method of extraction of such plants which are used for different therapeutic purposes for different age groups to heal various diseases. There were 114 plants were observed and recorded as medicinal plants in the study area and the documentation of this traditional knowledge is essential into the field of herbal research. Moreover, all efforts should be made to conserve these medicinal plants in a proper way for the health benefits of this community. Hence, conservation is important for such medicinal plants and also indigenous knowledge in the modern world.

Keywords: Ethnobotanical; Therapeutic Conservation; Gala Nefhi

Abbreviations: WHO: World Health Organization; ICF: Informant Consensus Factor.

\section{Background and Justification}

Plants provide people with food, medicines and other purposes of their various needs. Ethnobotany was a term first suggested by John Harshberger in 1896 to delimit a specific field of botany and describe plant uses. It was defined as "the use of plants by aboriginal peoples" [1]. Ethnobotanical studies based largely on qualitative methods and had all too often been just speculative exercises or have served only external interests, with the results of benefiting neither local people nor conservation [2]. Nowadays their chemical and genetic constituents are being increasingly explored for human benefit. Ethnobotanical studies based largely on qualitative methods and had all too often been just speculative exercises or have served only external interests, with the results of benefiting neither local people nor conservation [2]. Nowadays their chemical and genetic constituents are being increasingly explored for human benefit. According to World Health Organization (WHO) report more than $80 \%$ of the people in Africa depend on traditional medicine for their health care needs [3]. Plants have 


\section{Journal of Natural \& Ayurvedic Medicine}

played a very prominent role in the prevention and treatment of diseases since ancient times. In recent years, various plants are used as a subject to medical experiment. In particular, herbal plants are recognized as one of the intriguing subjects from which the extracts can be used in health care setting for future purpose however, because of global warming, deforestation, grazing, agricultural expansion and drought (sub Saharan country) many valuable medicinal plants rare on the verge of extinction [1]. Therefore, by evaluating their medical values, proper documentation, conservation and usage will be encouraged. In spite of the vast role and importance of Ethnobotanical contributions of medicinal plants in the primary health care, limited works have so far been done in the country. This study has therefore been to document the plants used in the traditional medical practices of the people of sub Zoba Gala-Nefhi together with associated Ethnobotanical and Ethnomedicinal knowledge and practices.

\section{Objectives}

The general objective of the present study is to study and document traditional medicinal plants, their management, conservation and associated with the indigenous plant knowledge of people in the study area.

The specific objectives of the study are:

- To classify, record traditionally important medicinal plants and for the treatment to humans

- To document the indigenous knowledge of the people on the use of medicinal plants

- To identify plant parts used for medicinal purposes, their method and route of administration.
- Conservation of medicinally important plants

\section{Materials and Methods}

\section{Description of the Study Area and Demography}

Central Region of Eritrea, also known as the Maekel or Maekel Region is an administrative region (or Zoba) in central Eritrea. The region was formed on 15 April 1996, from the historical province of Hamasien. The region is located on the central plateau, and sits at an average of about 2,250 meters (7,380 ft.) above sea level. It contains Asmara, the capital and largest city of Eritrea. The region is divided into sub-regions; Ghala Nefhi, Berikh, North Eastern, North Western, Sere-jaka, South Eastern and South Western, while Asmara forms a separate administrative area. It is the smallest region in area, and contains the major city and national capital, Asmara. Maekel is situated inland, and borders Anseba to the north-west, the Northern Red Sea region to the northeast, the Debub (Southern) region to the south, and GashBarka to the west. And Gala Nefhi is one of the seven Sub Zoba of Zoba Maekel. The Sub Zoba Gala Nefhi is composed of thirty-three villages which are governed under seventeen local administrations. The majority of the population in Gala Nefhi belongs to the Tigrigna ethnic group. In terms of faith, local residents are mainly devotees of the Church. The altitudinal range of the study area (sub Zoba) varies lower from Adi-Tsenaf local administration to highest mountains of Adi-hawesha. The Sub Zoba has an estimated total population of 78,510 of 37,989 are males and 40,520 are females. In terms of family the population of the Sub Zoba is 19,850 (Figure 1).

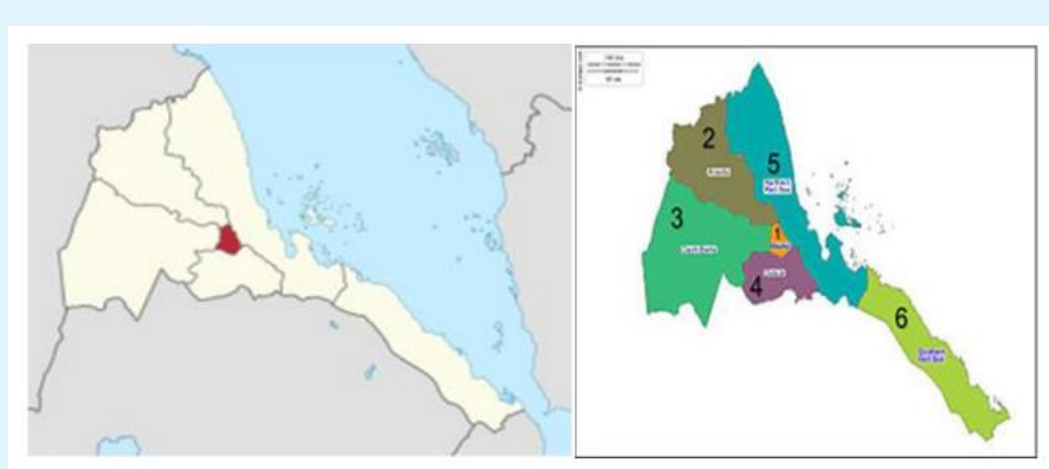

Figure 1: Map of the Study Area (the red and represented as number 1) as Zoba Maekel and 2-6 numbers as others Zoba of Eritrea (Google maps).

\section{Reconnaissance Survey}

Survey was conducted from Oct 2016 to April 2017 in the study site in order to obtain the data about medicinal plants, on the general physiognomy of vegetation and to identify sampling site. During the survey 16 


\section{Journal of Natural \& Ayurvedic Medicine}

representative sites (villages) distributed in the 17 local administrations were selected.

\section{Selection of Informants}

A total of 90 informants including 18 key informants for the local knowledge on traditional medical plants were selected. As pointed by Martin the selection of key informants is commonly systematic [4]. Furthermore, it was based on comments and recommendations from the religious leaders, elders, local administrators and from the community group and personal observation of the researcher. Thus, key informants were identified, later interviewed, and followed for further detailed discussion.

\section{Data Sources}

Ethnobotanical data were obtained from both primary and secondary sources. The primary sources were interview and group discussion in the field of the study area, whereas the secondary data sources are from various and relevant literature review.

\section{Ethnobotanical Data Collection}

The study has been carried out by interviewing the inhabitants in different villages under various local administration of sub Zoba Gala-Nefhi between the months of October 10, 2016 to April, 2017. The information, including the various data sets such as local names, parts of plants used, methods of preparation, methods of administration, doses, ailments and diseases treated, duration of the treatment were obtained from local people through individual interviews. The selection of respondents from each village was based on the following criteria: that they have been living in the sub Zoba for many years, use plants as the main medicine or identified as medicinal plant extractors. The information was checked with other areas, neighboring villages, to verify the accuracy. Informants were asked how, when, in this cases, both the harmful and useful effects of the used plants in detailed questions. Ethnobotanical techniques were employed to collect data on knowledge and management of medicinal plants used by the local people in the study area. The methods used for Ethnobotanical data collection were semi-structured interviewed following. Martin and Cotton, field observation and group discussion as described below [4,1].

Informant consensus: During data collection, informants were visited in order to confirm and use the reliability of Ethnobotanical information. Before the interviews, informants were instructed carefully about the method and encouraged to admit if they did not know the medicinal plant species or its uses.

Semi-structured: A list of questions was prepared that covered in discussion with the informants in a particular order. The interview was guided to cover the key topics on the checklist while leaving room to pursue any relevant subject brought up by the interviewee. All of the interviews were held in Tigrigna, the language of the local people and the researcher. The place and the time for discussion were set based on the interest of the informants. The status of all the medicinal plants was recorded as abundant, less abundant, rare or very rare as per healer perception during the semi-structured interviews.

Field observation: Field observations were carried out with local people, guidance from the elders of the village, and interviewed informants. And habitat, habit, abundance and distribution of plants were recorded in the given area.

\section{Ethical Consideration}

Involving indigenous peoples and sharing their acumen would permit the co-existence of knowledge and practices, which could enhance sustainability and include ethical considerations [5]. Gathering the old wisdom among local people in general and old people in particular, would offer an opportunity for paying respect to them. It would also enhance self-esteem among young generation and make them proud of the richness of the knowledge past in their community [5]. It would also allow the management of the knowledge based on their local indigenous knowledge. Special ethical considerations were taken based on the cultural view of the local communities in the study area. In view of these considerations, approaching of the informants was very systematic. By telling the fact and convincing each informant following his or her culture strictly. They were also informed that the objective of the research is not for commercial purpose but for academic reasons. In so doing, the informants in the study site were well informed about the objective of the research before the starting of data collection and/actual works. Finally, most informants accepted the idea and came to reach in agreement.

\section{Voucher Specimen Collection}

Specimens of medicinally useful plants were collected from various habitats at the spot during guided field work, numbered, pressed, and dried for identification. Identification of specimens was carried out both in the field and in and in Eritrean Institute of Technology, 


\section{Journal of Natural \& Ayurvedic Medicine}

Department of Biology's Herbarium Unit. Then after, nomenclature determination was carried out using Flora of Eritrea and Ethiopia and other available taxonomic literatures, the voucher specimens were kept at EIT Herbarium Unit.

\section{Vegetation Description}

Two approaches were used in describing the vegetation of the study area. In the first approach information was gathered from informants following the emic categorization technique i.e. Categorization by indigenous people based on their own indigenous knowledge. The second one was described and classified through repeated curious visual observation following the etic classification technique of Ethnobotany as described by Martin [4]. In the latter case, morphological characteristics or general appearance of vegetation such as growth and life forms of the dominant or co-dominant plants were focused on.

\section{Ethnobotanical Data Analysis}

The collected Ethnobotanical data were analyzed following survey and analytical tools for Ethnobotanical methods, which is recommended by Martin [4]. Appropriate software IBM SPSS, statistical version 2.0, and descriptive statistics were used. Informant consensus factor, preference ranking, direct matrix ranking and paired comparison were computed to assess the degree of effectiveness of certain medicinal plants against human being. The Informant Consensus Factor (ICF) was calculated for each category to identify the agreements of the informants on the reported cures for the group of ailments. The ICF is calculated as follows: number of used citations in each category (nur) minus the number of species used (nt), divided by the numbers of use citations in each category minus one [6].

$$
I C F=\frac{n u r-n t}{n u r-1}
$$

Preference ranking: Preference ranking were included in pre-designed semi-structured interview items. It was conducted following Martin for six medicinal plants in treating diseases [4]. The key informants were selected to identify the best preferred medicinal plants for the treatment of ailments based on their personal preference or perceived degree of importance in the community. They were informed to assign the highest value (5) for the most preferred plant species and the lowest value (1) for the least preferred ones. Finally, the values were summed up and the ranks given to each plant.

Direct matrix ranking: Direct matrix ranking was conducted following Cotton (1996) on ten multipurpose medicinal plants [1]. Informants were asked to order the items by considering several attributes one at a time. Using numerical scale in which the highest number is equal to the most preferred item, whereas, the lowest to the least one. Then the informants were asked to rate their preferences. Direct matrix ranking exercise was conducted for 10 multipurpose medicinal plants to determine the main cause for over harvesting of the respective plants.

Paired comparison: Paired Comparison is after identifying ten most important medicinal plants based on their medicinal values as perceived by the informants, the paired comparison was employed as described by Martin [4]. Paired comparisons on the eight most effective plants in treating health problems were conducted using random number table and flipping coins.

\section{Results}

\section{Samples of Informants}

Age group and gender of the informants: Informants in the study area can be represented under three age groups the Young age (25-40), Middle age (41-55) and Elders (56-91). The highest number is, in the age group between 56 and 91 . Information was gathered from 90 (51 females and 39 males) people using semi-structured Questionnaire. The number of informants in terms of gender is almost proportional (Table 1).

\begin{tabular}{|c|c|c|c|c|}
\hline Age group in yrs & Female & Male & Total & \% \\
\hline $25-40$ & 14 & 2 & 16 & $17.80 \%$ \\
\hline $41-55$ & 7 & 8 & 15 & $16.70 \%$ \\
\hline $56-91$ & 23 & 36 & 59 & $65.50 \%$ \\
\hline Total & 44 & 46 & 90 & $100 \%$ \\
\hline
\end{tabular}

Table1: Number, Age and Gender of the Informants. 


\section{Journal of Natural \& Ayurvedic Medicine}

Educational status of informants: Majority of the informants (58.8\%) were uneducated, but traditionally knowledgeable farmers, whereas $22.2 \%$ and $18.8 \%$ have formal and church education respectively (Table 2). The farmers and the young ones are free to tell the information on medicinal plants, whereas the highly traditionally skilled persons especially the key informant hide some information.

\begin{tabular}{|c|c|c|c|c|}
\hline Educational status & Male & Female & Total & \% \\
\hline Un-educated/illiterate & 28 & 25 & $58.90 \%$ \\
\hline Formal education & 12 & 8 & 20 & $22.30 \%$ \\
\hline Church education & 17 & 0 & 17 & $18.80 \%$ \\
\hline Total & 57 & 33 & 90 & $100 \%$ \\
\hline
\end{tabular}

Table2: Educational status of the informants.

Marital status of informants: As shown in the Table 3

\begin{tabular}{|c|c|c|c|c|}
\hline Marital status & Male & Female & Total & \% \\
\hline Married & 38 & 47 & 85 & $94.40 \%$ \\
\hline Single & 1 & 3 & $4.50 \%$ \\
\hline Divorced & 0 & 1 & 1 & $1.10 \%$ \\
\hline Total & 39 & 51 & 90 & $100 \%$ \\
\hline
\end{tabular}

Table 3: Marital status of the informants.

Traditional medicinal plant use knowledge transfer: Most of the traditional knowledge of medicinal plants is passed along the family line from Parents (60\%) followed by observation (32\%), trial and error (5\%) and other sources (3\%) (Figure 2).

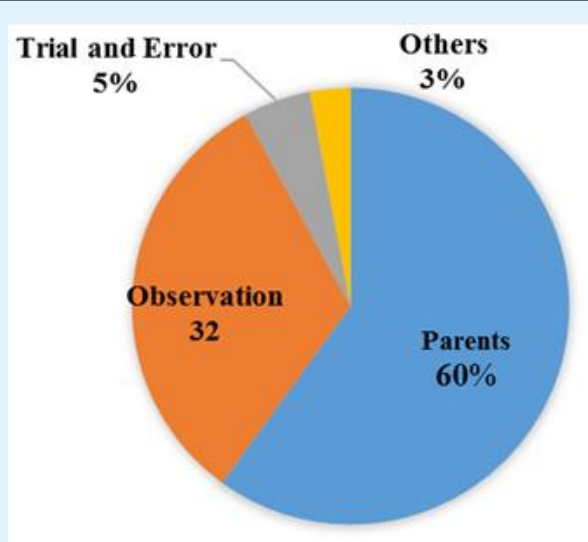

Figure 2: Traditional Medicinal Plant Use Knowledge Transfer.

\section{Medicinal Plants in the Study Area}

Ethnomedicinal plants used to treat human ailments: A total of 114 medicinal plant species, belonging to 55 families were recorded (Table 4). The most widely used species belonging to the families Fabaceae, Lamiaceae and Solanaceae.

\begin{tabular}{|c|c|}
\hline Family's Name & Number of species \\
\hline Fabaceae & 12 \\
\hline Lamiaceae & 10 \\
\hline Solanaceae & 7 \\
\hline Asteraceae & 5 \\
\hline Euphorbiaceae & 5 \\
\hline Anacardiaceae & 5 \\
\hline Rhamnaceae & 4 \\
\hline Rutaceae & 4 \\
\hline Poaceae & 3 \\
\hline Myrtaceae & 3 \\
\hline Amaranthaceae & 2 \\
\hline Apocynaceae & 2 \\
\hline Apiaceae & 2 \\
\hline Alliaceae & 2 \\
\hline Ranunculaceae & 2 \\
\hline Cucurbitaceae & 2 \\
\hline Combretaceae & 2 \\
\hline Oleaceae & 2 \\
\hline Polygonaceae & 2 \\
\hline Celesteraceae & 2 \\
\hline Ebenaceae & 2 \\
\hline Others 34 family & 1 \\
\hline
\end{tabular}

Table 4: Medicinal plants and their families that are used to treat human ailments. 
Among the cited traditional medicinal plant species in the study area, more than half (59\%) of the total were found in natural habitat, about $18 \%$ of the medicinal plants were found to be home garden while $15 \%$ species were grouped under natural habitat and home garden and $8 \%$ were found in markets (Figure 3 ).

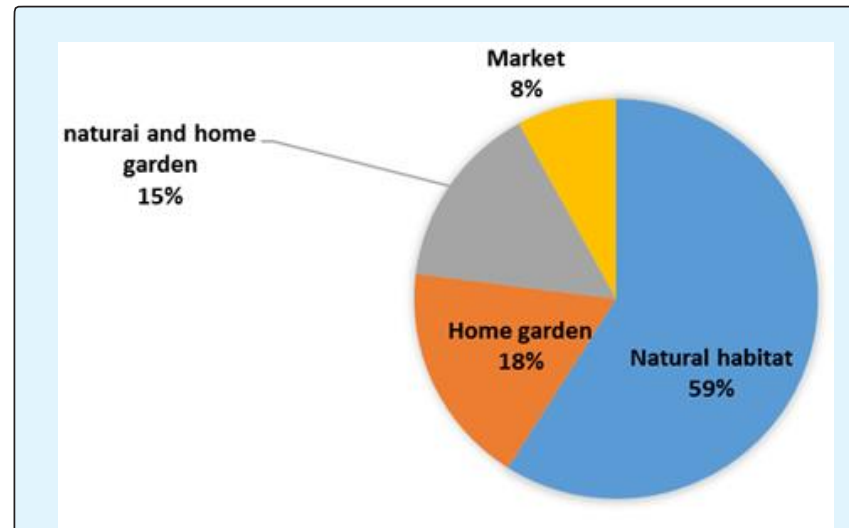

Figure 3: Traditional medicinal plant species.

Conditions of preparations of traditional medicine in the study area: A large number (85\%) of medicinal plants were cited to be used in fresh form in remedy preparations. Relatively few medicinal plants $(12 \%)$ in dried form and the rest very few medicinal plants (3\%) were reported to be used as dried and fresh forms (Figure 4).

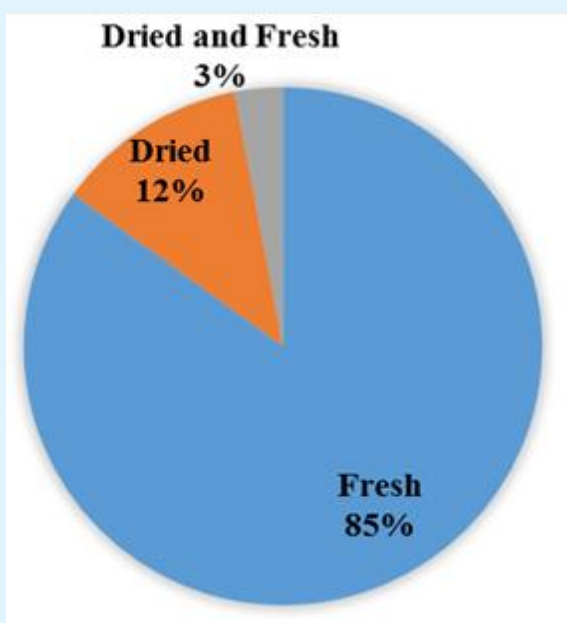

Figure 4: Condition of Preparation of Traditional Medicine.
Plant parts used and modes of preparation: The most widely used plant part for the preparations of remedy were leaves, which account for (42\%) followed by fruits $(24 \%)$, stem $(12 \%)$, latex $(12 \%)$, roots $(9 \%)$ and flower (1\%). The medicinal plant parts are processed in various forms crushing and harmonizing in water and/or other solvents and as crude (Figure 5).

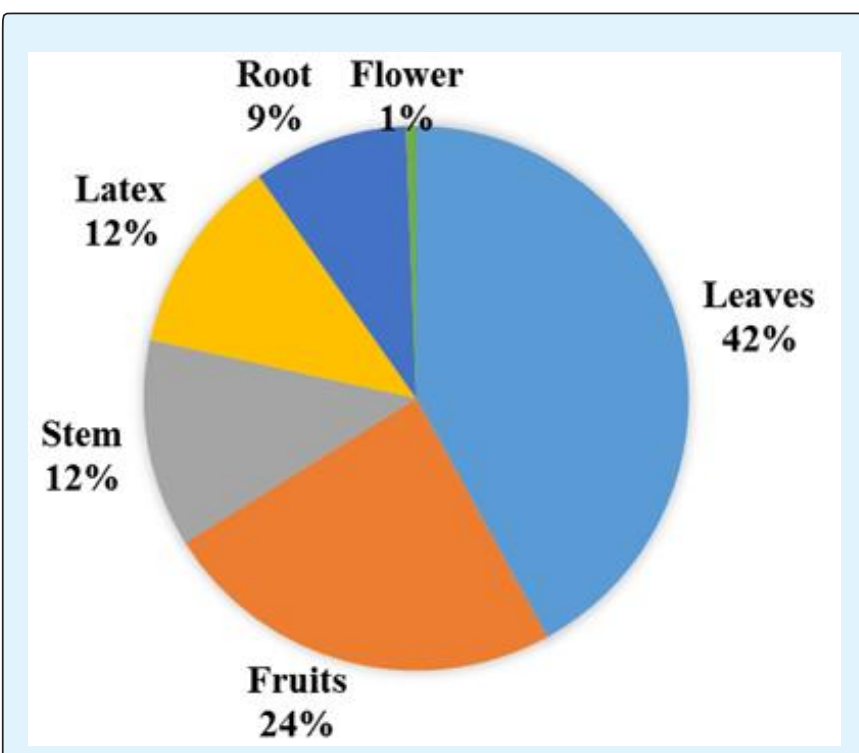

Figure 5: Plant parts used and modes of preparation.

\begin{tabular}{|c|c|c|}
\hline Types of Preparation & Number of Plants & (\%) \\
\hline Boiling & 31 & $22.30 \%$ \\
\hline Unprocessed & 23 & $16.54 \%$ \\
\hline Roasting & 19 & $13.66 \%$ \\
\hline Crushing & 15 & $10.79 \%$ \\
\hline Smoking/inhaling & 11 & $7.91 \%$ \\
\hline Crushed \& taking solution & 10 & $7.19 \%$ \\
\hline Chewing/spiting & 8 & $5.75 \%$ \\
\hline Powdering & 7 & $5.03 \%$ \\
\hline Latex collection & 7 & $5.03 \%$ \\
\hline Rubbing & 5 & $3.59 \%$ \\
\hline Others & 3 & $2.10 \%$ \\
\hline Total & 139 & $100 \%$ \\
\hline
\end{tabular}

Table 5: Types of preparation of herbal medicine.

Dosage and route of administration: Dosages were estimated using lid spoons for powder preparations; Cups ('beaker', 'tassa 'finjal') and Mug glasses for liquid mixtures to be administered and numbers in some cases 


\section{Journal of Natural \& Ayurvedic Medicine}

('handfuls') for leaf, seed and fruits. The most favored administration routes are oral, 59 plant species (42.14\%) followed by dermal 47 plant species $(33.57 \%)$. Other routes of administration are stated in Table 6.

\begin{tabular}{|c|c|c|}
\hline Mode of Administration & $\begin{array}{c}\text { Number of } \\
\text { Medicinal Plant }\end{array}$ & (\%) \\
\hline Oral & 59 & $42.14 \%$ \\
\hline Dermal & 47 & $33.75 \%$ \\
\hline Nasal & 15 & $10.71 \%$ \\
\hline Nasal \& Oral & 12 & $8.57 \%$ \\
\hline Eye & 4 & $2.85 \%$ \\
\hline Dermal \& Anal & 2 & $1.42 \%$ \\
\hline Dermal \& Oral & 1 & $0.70 \%$ \\
\hline Total & 140 & $100 \%$ \\
\hline
\end{tabular}

Table 6: Dosage and route of administration.

Informant consensus: The usage report of medicinal plants is called informant consensus or respondent consensus. Twelve top medicinal important plants were selected by fifty and above respondents. This indicated that, some medicinal plants are widely used than others. For example, Schinus molle, which stood first were cited by (93.3\%) informants, whereas Aloe elegance and Foeniculum vulgare are cited by (91.1\%) and (84.4\%) informants respectively. The last one from the top selected medicinal plans accounts for $50 \%$ of the informant consensus.

\begin{tabular}{|c|c|c|c|}
\hline Scientific name & $\begin{array}{c}\text { Number of } \\
\text { citations } \\
\text { (frequency) }\end{array}$ & I.consensus & Rank \\
\hline Schinus molle & 84 & 93.3 & 1 \\
\hline Aloe elegance & 82 & 91.1 & 2 \\
\hline Foeniculum vulgare & 76 & 84.4 & 3 \\
\hline Datura stramonium & 74 & 82.2 & 4 \\
\hline Ruta chalepensis & 72 & 80 & 5 \\
\hline Becium gradiliflorum & 66 & 73.3 & 6 \\
\hline Lepidium sativum & 63 & 70 & 7 \\
\hline Ziziphus spina-christi & 61 & 67.7 & 8 \\
\hline Acacia etbaica & 60 & 665.7 & 9 \\
\hline Azadirachta indica & 60 & 66.7 & 10 \\
\hline Nicotiana glauca & 59 & 65.5 & 11 \\
\hline Citrus limon & 56 & 62.2 & 12 \\
\hline
\end{tabular}

Table 7: Twelve most widely used medicinal plants.

Informant consensus factor: The highest ICF (0.75) value was associated with sun stroke/evil spirit and the least one (0.085) was associated with diseases related to internal and sense organs (Table 8).

\section{Discussion}

\begin{tabular}{|c|c|c|c|}
\hline Diseases & Ns & Nuc & ICF \\
\hline $\begin{array}{c}\text { Diseases related to gastrointestinal } \\
\text { problems }\end{array}$ & 45 & 87 & 0.48 \\
\hline $\begin{array}{c}\text { Diseases related to dermatological } \\
\text { problems }\end{array}$ & 49 & 81 & 0.4 \\
\hline $\begin{array}{c}\text { Organ diseases such as: liver, heart, } \\
\text { kidney, ear, eye, sex-organs etc }\end{array}$ & 44 & 48 & 0.09 \\
\hline $\begin{array}{c}\text { Diseases related to respiratory } \\
\text { problems: cough, flu, TB etc }\end{array}$ & 22 & 53 & 0.59 \\
\hline $\begin{array}{c}\text { Diseases related to malaria, hepatitis, } \\
\text { hepatomegaly and splenomegaly }\end{array}$ & 11 & 15 & 0.42 \\
\hline $\begin{array}{c}\text { Diseases related to sun-stroke and } \\
\text { evil spirit }\end{array}$ & 10 & 37 & 0.75 \\
\hline
\end{tabular}

Table 8: ICF by category of diseases (Key: Ns-number of species, Nuc-Number of use citation).

It was recorded 114 plant species of medicinal importance were noticed and documented. Most of these medicinal plants are harvested from natural stands followed by home garden. They are also found in natural forest, hills, mountains, churches, home gardens, rivers and roadsides. They are the predominant sources of general medicine for traditional healers. Shrubs were found to be the most dominant growth forms in the preparation of traditional remedies followed by herbs, trees, climbers and trailing herbs and different plant parts. People in the study area use medicinal plants not only for healthcare, but also as financial resources.

\section{Acquisition, Threat, Transfer and Basic Information of the TMP Knowledge}

The age of the informants lies between 25 and 91 years. The highest number is, in the age group between 56 and 91. This shows that the elders were more knowledgeable because of the many years accumulated experience transferring to the next generation.

It has been found that the main sources of TMK are parents $60 \%$ followed by observation $32 \%$, trial and error $5 \%$ and other acquaintances and knowledgeable persons $3 \%$. Medicinal plant knowledge, use and transfer of knowledge to the young generation can be affected by religious beliefs, modernization, acculturation, and environmental change [7]. Ethnomedicinal knowledge diminishes with death of elderly knowledgeable members of the community since only a few young people are willing to acquire the knowledge $[8,9]$. In a similarly, the respondents in the study site also reported that the 


\section{Journal of Natural \& Ayurvedic Medicine}

transmission of TK is disrupted because of modernization and rapid changes in people's life style.

Indigenous people revealed that gathering and processing of many medicinal plants were restricted to traditional medicinal practitioners and their trainees. At family level, it is restricted to the elders (men and women), followed by elder son or daughter or their trustworthy person when the mother or the father is getting old or near to die [8]. The death of elderly custodians of certain traditional knowledge will mean loss of certain practices unless they are passed on to younger generations since folk knowledge among the sub Zoba people like many traditional tribes, is orally transmitted.

It is observed that more than in oral or written communication skill transfer of knowledge system is in their beliefs and norms. However, in the study area, knowledge has been transferred from one generation to the next through the interaction of the communities. Most respondents transfer their knowledge to their family. This means that most of the TK of MPs is passed along the family line. First-born children in the family are the main holder of responsibility in keeping the information and they are successor of their parents as well. Few others share to trustworthy and close neighbors and other blood relation persons. Exchange and knowledge sharing are also common among intimate key informants.

A major problem observing in the study was that few of highly traditional skilled and knowledgeable persons are rigid to pass the information. This is because, first, it is a means of income generation and their livelihood. Second, they believe that the medicinal plant is less effective in treating a certain ailment if everybody knows it. On the other hand, most of the time knowledgeable persons were locally said to be 'Debtera' or 'Tenqualay'. They were also condemned as 'Belaei qotseli (leaf eaters). Because of the above mentioned difficulties, the traditional medicine practitioners had forced to keep their knowledge and practices in secret. In comparison with males, females are sensitive and afraid of the taboo words forwarded by the local people. That is why the number of female informants in the study area was less than males.

\section{Medicinal Plants Used to Treat Human Ailments}

The number of medicinal plants collected in this Ethnobotanical study was 114; belonging 55 families, as listed in Table 5. The data presented in this study indicated that few of the claimed medicinal plants are used as the treatments of many types of ailments. The medicinal plants for example Aloe elegance, used to treat 9 diseases, Azadirachta indica used to treat 4 diseases, Balanites aegyptiaca used to treat 4 diseases, Calpurnia aurea used to treat 4 diseases, Coffea Arabica used to treat 4 diseases, Ficus carica used to treat 4 diseases Lepidium sativum used to treat 4 diseases, Schinus molle used to treat 4 diseases Solanum nigrum used to treat 4 diseases, many others like Achyranthes aspera used to treat 3 diseases. The study also showed that most of the medicinal plants cure more than two ailments whereas, relatively some used only the treatment of one type of disease. The preference ranking indicated that, the most preferred MPs to treat malaria among 12-selected plant species was Becium gradiliflorum was the most preferred one and followed by Allium sativum, Aloe elegance, Ocimum forskolei, Salvia schimperii, Ficus carica and Cicer arietinum (Table 4). Direct matrix of randomly selected 11 medicinal plants with different uses other than medicinal value on a given use criteria revealed that medicinal plants broadly collected for different purposes (Table 4). Paired comparison of 8 selected medicinal plants out of 20 plant species that were used to treat fungal diseases based on informant consensus showed that Olea europeana, Cuspidate, Datura stramonium, Azadirachta indica, Acacia etbaica, Vernonia amygdalina, Vernonia schimperii, Aloe elegance and Argemaone Mexicana Stood $1^{\text {st_ }} 8^{\text {th }}$ respectively (Table 5).

As seen in Table 8, the largest number of the remedies (49) in the study area was used against dermatology problems such as fungal infection, dandruff, nail inflammation, skin inflammation and "Zuee", cuts, wounds, scabies burns, leishmaniasis and eczema. Gastrointestinal was treated by the second largest number of remedies (45) such as stomachache, gastritis, diarrhea, dysentery, constipation, abdominal helminthes, vomiting, and tapeworm. The third largest medicinal plant species (44) was used against Organ diseases such as: liver, heart, kidney, teeth, ear, eye and sex organs, followed by remedies treating respiratory problem, malaria and sun stroke/evil spirit (22), (11) and (10) respectively. On the other hand, the ethnobotanical results showed that the highest ICF (0.75) value was associated with sun stroke/evil spirit problems followed by diseases related to respiratory problem $(0.59)$, gastrointestinal problems (0.48), malaria and other related diseases $(0.42)$, diseases related with dermatology $(0.4)$, and the category of the lowest ICF (0.085) value was associated with organ diseases such as teeth, liver, heart, ear and eye etc (Table 6). This shows that medicinal plants, which have higher ICF values, are assumed effective in treating a certain ailment. Nugusse Amsalu, reported high proportion of remedy for the treatment dermatological/skin problems 


\section{Journal of Natural \& Ayurvedic Medicine}

(0.74) followed by gastrointestinal problems (0.66), in Ethiopia [10].

\section{Sources and Habits of the Medicinal Plants}

According to an estimate, 90 per cent of plant material for a medicinal purpose is harvested from wild sources (forests) [11,12]. It includes a wide range of non-timber forest products (NTFPs) in the form of roots, seeds, skin, bark, flowers, fruits and leaves. About $70 \%$ of the total is still growing in the wild [13]. Most of the medicinal plants utilized by the African people are harvested from natural habitats [14]. Similarly, in the study area, most medicinal plants (59 \%) are harvested from natural habitat in different natural communities, home garden (18\%), both in natural and home garden (15\%) and $(8 \%)$ of the medicinal plants are available in markets of the study area (Figure 3). The current findings of the study area show that the most widely used medicinal plants habits in the study area are shrubs followed by herbs. Results of this findings agreed with the findings of revealed that shrubs are the most commonly used in their respective different study sites of Ethiopia and Eritrea [8,15-19].

\section{Conditions, Plant Parts Used and Modes of Preparation}

The result in the conditions of plant part used indicated that most medicines (85\%) are prepared from fresh plants and plant parts; whereas (12\%) and very small $(3 \%)$ were prepared from dried and dried or fresh respectively (Figure 4). Similar results were reported in the finding [20]. Analysis of the data revealed that, leaves (42\%) and fruits (24\%) were the most widely used plant parts in preparation of remedies followed by others such as stem, latex, root and flowers (Figure 5). Previous reports in Ethiopia have also shown that leaves were the most commonly used and followed by roots to treat various health problems $[15,21]$. During the preparation of traditional medicine from plants, the methods of preparations used by traditional healers were boiling, crushing, smoking/inhaling, squeezing, powdering, and mixing with solvents like water, honey and butter in liquid preparations. Most of the preparations of traditional medicinal plants involved the use of solvents and the solvent used is water. Butter and honey are also used in paste preparations. Additives like sugar, honey, and coffee were used in most of the remedy preparations to make them tasty during taking the medicine. This is to reduce the bitterness of the medicine and initiate the patient to take it.

\section{Dosage, Lack of Precision, and Route of Administration}

The measurements used to determine the dosages are not standardized and depend on the age, physical appearance of the patient, degree of the illness, diagnosis and experience of individual healers or knowledgeable person. Children are given less than adults, such as, half of a coffee cup whereas; an adult is given up to one glass depending on the type of illness and treatment in the study area. Dawit Abebe reported that lack of precision and standardization drawback for the recognition of the traditional healthcare system [22]. The amounts of remedy and prescription rates were generally dependent on the degree and duration of the ailment. Therefore, this study revealed that while there may be scope for finetuning the methods, traditional treatments are not entirely devoid of all measurement and standards. For example, almost all informants demonstrated awareness of the toxicity of some plants and specific plant parts when administered in large doses. In some cases, the healers will give antidotes such as milk coffee if the doses are beyond the patients' capacity.

The informants in the study area reported that some MPs including Datura stromonium, Aloe elegance, Ricinus communis, Verbascum siniaticum, Euphorbia abyssinica, and Croton macrostychus are poisonous to man if not handled with proper care. Though these medicinal plants do have side effects, they are effective in treating different ailments. This emphasis how much the local people aware the use and side effects of MPs. However, the medicinal properties of many plants have been scientifically proven in recent years. For example, Ricinus communis for the treatment of infection, Verbascum sinaiticum for the treatment of tapeworm, and Phytolacca dodecandra as a molluscicide in the control of schistosomiasis are plants from Eritrea which have been proven as effective and safe $[19,23]$.

The medicinal plant preparations were applied through different routes of administration. The common administration routes are oral $59(42.1 \%)$ followed by dermal $47(33.8 \%)$. Other roots of applications are nasal, ear, anal, nasal \& oral, and dermal, genital \& anal (Table $6)$. Similar results were observed by who reported that the leading route of application used in northern Ethiopia is oral which accounted for $42 \%$ [24]. Those taken through nasal are either smoked or boiled in water and the patient inhales the smoke or the stem being covered with cloth. 


\section{Journal of Natural \& Ayurvedic Medicine}

\section{The Ten Top Medicinal Plants in the Study Area}

From all medicinal plants (10 species) that had high informants' consensus of $50 \%$ and above (Table 8 ) and are very commonly used plants to treat different humanly ailments were reported and are described below:

Schinus molle: (Anacardiaceae) for diarrhea, abdominal pain, cold and leishmaniasis [25]. Aloe elegance (Aloaceae) for anti-fungal, dandruff, HIV, malaria, arthritis, wound healer, anti-bacterial, diabetics \& abdominal pain, anti-fungal and antibiotics, the latex is also used to treat the impotency [19,24]. Datura stramonium (Solanaceae) for antibacterial and antifungal treatment [15]. Dodonaea angustifolia: (Sapindaceae) to treat diarrhea and bone fracture and also used to treat Leishmaniasis [25]. Allium sativum (Alliaceae) for hypertension, malaria, asthma, roots were used against toothache and leaves are used against coughing [26,27]. Ruta chalepensis (Rutaceae) to treat cough, cold, stomachache, the root is employed even influenza $[10,20]$. Ziziphus spina-christi (Rhamnaceae) to treat cough \& fungal migraine and also to treat jaundice and malaria [10]. Rhamnus prinoides (Rhamnaceae) to treat cough tonsillitis and also used as antibiotic and also to treat TB, bronchial infection, malaria and diabetes [27,19]. Rumex nervosus (Polygonaceae) to treat Muscle contraction and Traditional sauna (Appendix 3) this plant species used in traditional medicine to treat various diseases such as diabetes, cholesterol, anemia, itching, rheumatism, gastritis and enlarging of the female breast [28]. Foeniculum vulgare (Apiaceae) to treat Hypertension, Cough, Abdominal pain \& Obesity in the study area. The use of the plant to treat cough and reduce obesity has been recorded in Eritrea [19,29].

\section{Threats, Management and Conservation of the Medicinal Plants}

Biodiversity loss in Africa is usually caused by expansion of investment activities, deforestation, overgrazing and expansion of agricultural activities, poverty and lack of appropriate policies that encourage conservation and management of biodiversity [1]. It is reported that several medicinal plants have already disappeared from their common habitat and some of them are at risk of extinction. People or traditional healers are forced to travel a long distance to obtain some medicinal plants [1].

As in other parts of Eritrea, plant resources are vital for the livelihood of the sub-Zoba Gala Nefhi people. However, the resources are eroded from time to time because of the increment of population. Associated with this, the demand of agriculture is high and therefore clearance of vegetation and/or forests are high.

As indicated in Table 7 the main threats on medicinal plants in the study area are agricultural expansion $(22.2 \%)$, grazing $(21.3 \%)$, drought $(20 \%)$, fire wood $(19.3 \%)$ and construction (16.6\%). In the study area, natural forests such as the Adi-ke, Areberubu area and other few villages are also serving as conservation for many medicinal plants [19]. These natural forests are being protected by the local people in collaboration with the local administration. On the other hand, the healers bring and plant the most threatened medicinal plants in their home gardens. In his findings reported that, the home garden is a strategic and ideal farming system for conservation, production and enhancement of medicinal plants and valuable indigenous knowledge [30,31]. Likewise, medicinal plants which have additional uses in the area, such as ornamental, fuel, forage, spice, food and soil conservation were planted on home gardens and farmlands. Plants for example, Allium sativum, Foeniculum vulgare, Ruta chalepensis, Schinus molle, Rhamnus prinoides and few others were commonly planted. This implies that endangered species are the focus of ex-situ conservation. Therefore, it must be noted that sustainable medicinal plant management and conservation is not an option but imperative for rural health and community well-being especially primary health.

\section{Conclusion and Recommendation}

It can be concluded that, the documentation of this traditional knowledge is inevitable to throw a light in to the field of herbal research and to improve socioeconomic development of the people. Moreover, all efforts should be made to conserve these medicinal plants in a proper way for the health benefits of this community. This work is based on the indigenous knowledge on medicinal plants and methods of treatment against common ailments prevailing among the people of the sub region Gala-Nefhi.

Based on the results and the conclusions given above, the following recommendations are

- Traditional herbalists should be acquainted with fundamental principles of medicines

- Medicinal properties of the plant species used should be properly known and well documented

- All efforts should be made to conserve these medicinal plants

- Create awareness to encourage the population to conserve the threatened and endangered plant species in their natural habitats and home-gardens. 


\section{Journal of Natural \& Ayurvedic Medicine}

\section{References}

1. Cotton CM (1996) Ethnobotany: Principles and Applications. John Wiley and Sons Ltd. Chichister, England, pp: 347.

2. Hamilton AC (2003) Medicinal Plants and Conservation: Issues and Approaches. International Plants Conservation Unit, WWF- UK, pp: 43.

3. WHO (2000) World Health Organization General Guidelines for Methodologies on Research and Evaluation of Traditional Medicine, Geneva.

4. Martin GJ (1995) Ethnobotany: A method Manual. A 'People and Plants' Conservation Manual. Champman and Hall, London, pp: 268.

5. Emadi NL (2005) Indigenous pattern of conserving biodiversity: pharmacologic Implication. J Ethnopharmacol 63(3): 233-245.

6. Heinrich M, Ankli A, Frei B, Weimann C, Sticher O (1998) Medicinal plants In Mexico: Healer's Consensus and Cultural Importance. Soc Sci Med 47(11): 1859-1871.

7. Cunningham AB (1996) People, park and plant use recommendation for multiple uses zones and development alternatives around Bwindi. Impenetrable National Park Uganda. In: People and Plant Working Paper, UNESCO, Paris 4: 18-23.

8. Hunde D, Asfaw Z, Kelbessa E (2004) Use and Management of Ethnotanical Medicinal Plants by Indigenous People in Boosat, Welenchiti area. Ethiop J Biol Sci 3(2): 113-132.

9. Yemane B, Andebrhan M, Reddy KS (2017) Traditional Medicinal Plants used by Tigrigna Ethnic group in Central Region of Eritrea. IOSR Journal of pharmacy and Biology 12(3): 40-46.

10. Amsalu N (2010) Ethno botanical study of medicinal plants used in Farta Wereda, Southern Gonder, Amhara region, University of Addis Ababa a Master's of Science thesis, Ethiopia.

11. Tiwari KD, Yadau A (2003) Ethnobotanical Investigation of Some Medicinal Plants Availed by Gond Tribe of Naoradehi Wild Life Sanctuary, Madhya Pradesh. Anthropologist 5(3): 201-202.
12. Singhal R (2005) Medicinal Plants and Primary Health Care: The Role of Gender. PAGE, 70London. Journal of Health Management 7(2): 277-293.

13. Cole NH (1996) Diversity of medicinal plants in West Africa habitats. In; the biodiversity of African plants. In: Mesen V, et al. (Eds.), Proceedings 14th AETFAT Congress 22-27 August (1994) Wageningen, Netherlands, pp: 704-768.

14. Frankel OH, Anthony HDB, Burdon JJ (1995) The Conservation of Plant Biodiversity. Cambridge University Press, Cambridge, pp: 299.

15. Tamene B (2000) A Floristic Analysis and Ethno botanical Study of the Semi-Wet land of Cheffa Area, South Wello, MSc Thesis, Addis Ababa University Ethiopia.

16. Giday M, Ameni G (2003) An Ethnobotanical Survey on Plants of Veterinary Importance in Two Weredas of Southern Tigray, Northern Ethiopia. SINET: Ethiop J Sci 26(2): 123-136.

17. Lulekal E, Kelbessa E, Bekele T, Yineger H (2008) An Ethnobotanical study of medicinal plants in Mana Angetu District, southeastern Ethiopia. Journal of Ethnobiology and Ethnomedicine 4: 10.

18. Mesfin F, Demissew S, Teklehaymanot T (2009) An Ethnobotanical study of medicinal plants in Wonago Wereda, SNNPR, Ethiopia. Journal of Ethnobiology and Ethnomedicine 5: 28.

19. Yemane B, Medhanie G (2016) Ethnobotanical study of medicinal plants in sub-zoba Debarwa, zoba debub, Eritrea. Eritrean journal of science and engineering 2(1): 63-97.

20. Amenu E (2007) Use and management of Medicinal plants by Indigenous People of Ejaji Area (Chelya Wereda) West Shoa. An Ethnobotanical Approach, MSc Thesis Addis Abeba University, Ethiopia.

21. Giday M, Tekelehaimanote $\mathrm{T}$, Anmut A, Mekonnen $\mathrm{Y}$ (2007) Medicinal plants of the Shinasha, Agew-Awi, and Amhara people in northwest Ethiopia. Journal of Ethnopharmacology 110(3): 516-525.

22. Abebe D (2001) The role of medicinal plants in health care coverage of Ethiopia. The possible benefits of integration. In: Zewdu M, et al. (Eds.), Conservation and Sustainable Use of Medicinal Plants in Ethiopia, Proceedings of the National Workshop on 


\section{Journal of Natural \& Ayurvedic Medicine}

Biodiversity Conservation and Sustainable Use of Medicinal Plants in Ethiopia, 28 April-01 May 1998, IBCR, Addis Ababa pp: 6-21.

23. Russo L (2000) Ethiopia-Non-Wood Forest Products and Forest Services, FAO Forestry.

24. Abebe D, Ayehu A (1993) Medicinal Plants and Eenigmatic Health Practices of Northern Ethiopia. Addis Ababa, BSPE, pp: 511.

25. Getahun A (1976) Some Common Medicinal and Poisonous Plants Used in Ethiopian Folk Medicine. Addis Ababa University pp: 63.

26. Abbink J (1995) Medicinal and Ritual Plants of the Ethiopian South West an account of Recent Research. Indigenous Knowledge and Development Monitor 3(2): 6-8.

27. Iwu MM (1993) Handbook of African Traditional Medicinal plants. Boca Raton, Ann Arbor, London. CRC Press, pp: 43.
28. Berhane E (2001) Ethnobotany: A method manual. Medicinal application of Plants. Semhar, Asmara, (Tgrigna) Eritrea.

29. Weldeab S (2010) Legislative Regulation of Traditional Medicinal Knowledge in Eritrea vis-à-vis Eritrea's Commitments under the Convention on Biological Diversity: Issues and Alternatives. Law Environment and Development Journal 6(2): 37.

30. Asfaw $\mathrm{Z}$ (2001) The role of home gardens in production and conservation of medicinal plants. In: Zewdu M, et al. (Eds.), Conservation and Sustainable Use of Medicinal Plants in Ethiopia. Proceedings of the National Workshop on Biodiversity conservation and Sustainable Use of Medicinal Plants in Ethiopia, IBCR, Addis Ababa, Ethiopia pp: 76-91.

31. CSOD (2010) Central Statistical Office of Zoba Debub, Eritrea.

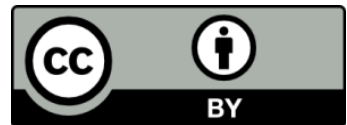

